J. Neurol. Neurosurg. Psychiat., 1955, 18, 53.

\title{
VISUAL HALLUCINATIONS OF THE SELF IN ORGANIC DISEASE
}

BY

\author{
KENNETH DEWHURST and JOHN PEARSON
}

\author{
From the Geriatric Unit, United Oxford Hospitals
}

There are few references to autoscopy in medical literature, and almost all recorded cases are to be found in Continental journals. Most frequently it has been noted in epileptics (Genner, 1947 ; and Lhermitte, 1951a, b). Sivadon (1937) describes the case of a doctor suffering from influenza who saw himself on his way to hospital; and Skvortzoff (1931) records similar visual aberrations in patients with functional disorders of the labyrinth. Nouët (1923) reported autoscopic hallucinations in a patient with a fragment of shrapnel lodged in the right temporal lobe. Hallucinations of the self have also been described in patients suffering from infectious fevers (particularly typhus), general paralysis of the insane, brain tumours, or post-traumatic cerebral lesions (Lhermitte, 1937, 1951a, b).

Three further cases of autoscopic hallucinations in association with organic lesions are presented. Those afflicted were fully aware that these visions resulted from their illness and were unreal; but whereas the first two patients were ill disposed to discuss the details of their experiences, the hallucinations of the third subject were so persistent as to provoke this sole presenting symptom.

\section{Case Reports}

Case 1 (R.I. 129664). - A male teacher aged 46 was admitted to hospital on December 19, 1952, complaining of malaise and vomiting. There was a four-day history beginning with a vague, uncomfortable feeling which lasted for 48 hours. Two days before admission he noticed the onset of a frontal headache of gradually increasing severity; at the same time he experienced nausea, and started vomiting the next day. The day before admission he was unable to pass urine, and had to be catheterized by his doctor. He felt drowsy and confused when admitted to hospital.

He was found to be an anxious, ill-looking man, with normal temperature and pulse. His pupils reacted equally to light and accommodation; there was no muscular weakness; the peripheral reflexes were completely normal, and there were no sensory abnormalities. There was, however, marked neck stiffness with a positive Kernig's sign. The optic fundi showed gross nipping of the veins, with silver wiring of the arteries : there was some retinal exudate but no haemorrhage or papilloedema. The pulse was regular; blood pressure $210 / 140 \mathrm{~mm}$. $\mathrm{Hg}$; the apex beat was to be felt in the fifth intercostal space $5 \frac{1}{2}$ in. $(14 \mathrm{~cm}$.) to the left of the midline, and there was a blowing apical systolic murmur. There was gross albuminuria.

Lumbar puncture on the day of admission showed a blood-stained, xanthochromic fluid. The serum and cerebrospinal fluid Wassermann reactions were negative. Two days after admission the blood urea level was 84 mg. per $100 \mathrm{ml}$; the kidneys could concentrate to a specific gravity of $1 \cdot 024$.

With complete rest in bed, the patient gradually recovered from his drowsiness and confusion. Further lumbar puncture confirmed the diagnosis of subarachnoid haemorrhage complicating malignant hypertension. During his stay in hospital he was given a subcutaneous injectior of hexamethonium bromide, which caused a mass incontinence and was not repeated. Hexamethonium bromide, $500 \mathrm{mg}$. twice daily by mouth, was started and this had a good symptomatic effect. On discharge the patient had no headaches, and felt quite fit in himself ; there was no sign of central nervous system disease.

On further questioning as to the exact nature of the start of his trouble (earlier he had said only that he " felt ill "), he confessed to having seen an image of himself. This was the first symptom of the present trouble and, indeed, was the only symptom for the first two days. His "double" persisted for the four days before his admission to hospital. It appeared quite solid as if seen in a mirror, dressed exactly as he was. It accompanied him everywhere ; at meal-times it stood behind his chair and did not reappear till he had finished eating. At night it would undress and lie down on the table or couch in the next room of his flat. The double never said anything to him or made any sign, but only repeated his actions : it had a constant sad expression. It was obvious to the patient that this was all a hallucination, but nevertheless it had become sufficiently a part of himself for the patient to draw a chair up for his double when he first visited his private doctor.

He saw the double on one occasion in hospital a few days after his admission. It was in the middle of the night; he saw the image dressed in pyjamas in the 
middle of the ward getting into an empty bed: the image vanished a few moments later. This was the only occasion on which the double was not carrying out exactly the same actions as himself.

The patient had had the same sort of hallucination when he had typhus fever at the age of 15. Then it had appeared on several occasions during a period of about four weeks, and would always lead him to leave his bed and take a drink. His doctor, in fact, had forbidden him to do just this. A brother of the patient had had similar hallucinations, but no details were available.

Since his discharge from hospital on January 31,1953 , it has not been possible to pursue any further investigations.

Case 2 (R.I. 163497, C.R.H. 1646).-A man aged 62 was transferred to Cowley Road Hospital, Oxford, on December 13, 1952, from the Radcliffe Infirmary, where he had been admitted on September 12, 1952, following a "stroke." He had been unable to give an account of himself : a history of amblyopia for a few hours, three weeks previously, together with severe headache for two weeks, was obtained from the relatives. Six days before admission he suffered an abrupt transient paraplegia lasting several minutes, followed by right hemiplegia on the day of admission. He was examined by Mr. Pennybacker, who diagnosed a progressive lesion in the posterior part of the left cerebral hemisphere ; a burr-hole biopsy carried out by him on October 4, 1952, revealed a multicystic malignant glioma of the left posterior temporo-parietal region.

On examination the patient was found to be a wellbuilt man of good nutrition, continent, but mentally retarded, with perseveration and memory defects. There was a right hemianopia with bilateral papilloedema, the left worse than the right. Pupils were equal but gave very poor reaction to light and accommodation. He had right lower facial weakness, also paresis of the right arm with exaggerated reflexes. The power of the left arm and leg was good. Weakness and exaggerated reflexes were found in the right leg. The plantar responses were right extensor, left flexor. Dubious hypalgesia of the right arm was found, but definite impairment of two-point discrimination in the right hand and arm. There were no other significant clinical findings.

On October 29, 1952, seven weeks after admission, the patient began to experience visual hallucinations. He first saw a number of white lights, but was not certain of the direction in which they moved. Occasionally he saw the figure of a middle-aged man " out of the corner of his eye". The image was always that of the same man, and was always seen in the right visual field, just over the supra-orbital angle. He could not recognize the man. There were no other sensory hallucinations at this time. This right-sided image became more persistent, but its features were always the same. On November 14, 1952, he was greatly agitated, as he had seen the image of himself, which was exactly "like looking in a mirror". He realized that it was a hallucination. It persisted for about one minute, during which time all his movements were reciprocated by the image. The hallucination of the man in his right visual field became more constant during the next two months. He also had further autoscopic hallucinations during this time; and, coinciding with the onset of autoscopy, the image in his right visual field always disappeared. Later the patient became irrational and had fits of persecution mania. On January 13, 1953, he became comatose, and died three days later. A post-mortem examination was carried out by Dr. Bosanquet, of the Department of Neuropathology, Radcliffe Infirmary, on January 18, 1953.

Examination of the brain showed herniation of the cortex (about $0.8 \mathrm{~cm}$. deep) through dural needle tracks in both parieto-occipital regions. The left parietotemporal area was expanded by a reddish tumour, 1.5 by $1 \mathrm{~cm}$., on the inferior surface of the left temporal lobe. Coronal section revealed a tumour mass (necrotic, haemorrhagic, and cystic, the whole traversed by large vessels) occupying almost the whole of the white matter of the left occipital lobe (Fig. 1). It appeared to be a

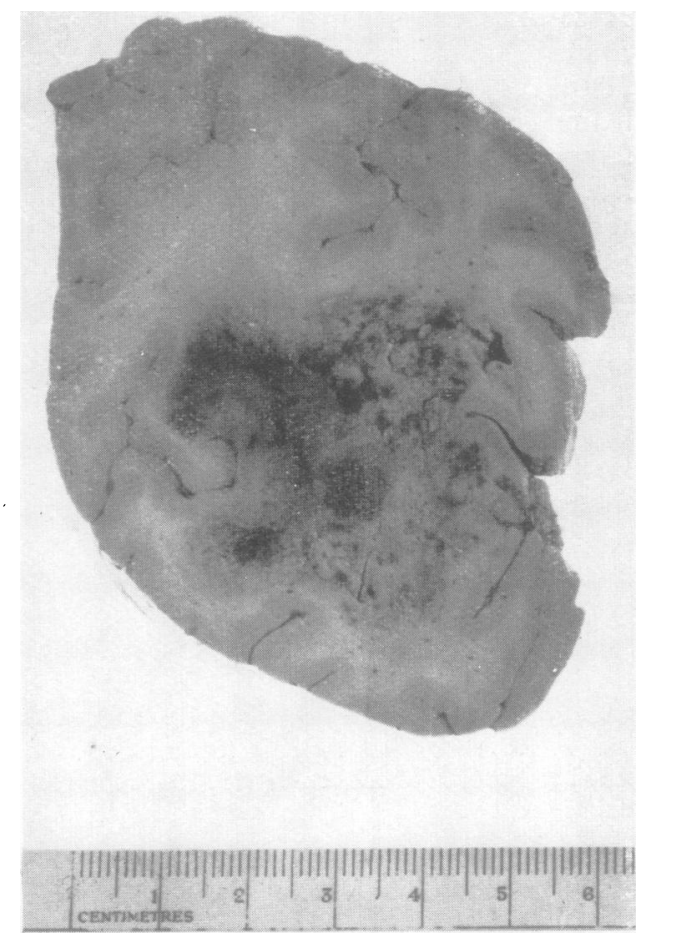

Fig. 1.-Case 2 : coronal section of the tumour in the left occipital lobe.

glioblastoma, $8 \mathrm{~cm}$. in length and $4 \mathrm{~cm}$. in diameter. The tumour did not involve the cortex, but there was marked anterior oedema so that the whole hemisphere was noticeably expanded. Severe cingulate herniation on the left with flattening of the anterior horn of the left ventricle was found ; the posterior horn was replaced by the tumour mass. The anterior horn was slightly 
dilated. On the inferior aspect of the left temporal lobe was a tumour nodule $1 \mathrm{~cm}$. in diameter. It was situated $1 \mathrm{~cm}$. anterior and $3 \mathrm{~cm}$. lateral to the main tumour mass. There was some upward herniation of the vermis, but otherwise the brain-stem and cerebellum were natural.

Case 3 (M.R.C. No. 1030). -A man aged 57 was admitted to hospital complaining of episodes during which he "saw himself". In 1917 his right eye was destroyed by a fragment of shrapnel which passed through the orbit into the right temporal lobe of the brain, where it is still lodged. The patient has a clear recollection of sustaining the injury, but lost consciousness a few hours later: he had post-traumatic amnesia for four or five days and was in hospital for six months.

In 1922 he first began to suffer from attacks of grand mal, about which he has only a hazy recollection. Usually there is no aura ; but on one occasion he did remember gazing at the leaves of a tree rustling in the wind. Gradually they began to change into "little coloured goblins " and immediately afterwards he lost consciousness. The patient has been told that during these fits (which usually occur at night) he always has convulsions, froths at the mouth, and often bites his tongue. He has had 10 to 20 such episodes in 20 years, the last occurring in 1942 .

The nature of these attacks altered in 1930, when he first began to see a black spot in front of his eye. "I've seen the $x$-ray of the bit of metal in my head and it looked just like that." The scotoma lasted intermittently for some hours : afterwards he saw the figure of a man. "I was in the doctor's surgery staring into the garden. Then I saw the man about four feet away to my left. It suddenly dawned on me who it was. It was me." These hallucinations of a normal-sized mirror image of himself lasted for about 10 days. His "double" seemed solid, but there was no feeling of affinity between them.

Seven years ago the patient had another curious experience. He was alone in a wood gathering sticks. " I knew that I was alone, yet suddenly I felt surrounded by hordes of people." This feeling, which lasted intermittently for about a week, was not accompanied by any hallucination.

In January, 1954 (one month before admission), the right-sided headaches which are a sequel of his original injury became more severe and more frequent. A fortnight later he again experienced visual hallucinations, which for the first three or four days tcok the form of multicoloured lights. Later they became more organized, and he saw " crowds of tiny figures all the colours of the rainbow-all myself". These figures approached and then receded. He also saw stairways and other interior parts of a house. "Sometimes it was my own house, other times I couldn't recognize it." Each episode lasted two or three minutes and was preceded by a feeling of nausea. At the time of his admission these hallucinations had become almost continuous; the remissions lasted only a few minutes and even then his vision was distorted. "The house across the road was much bigger than I knew it to be ; and the wireless in the corner of the room looked the most ridiculous thing you ever saw." He stressed the fact that during these latter episodes he was conscious, fully aware of his surroundings, and quite capable of carrying on a conversation.

The patient, who farms a smallholding, is teetotal and a non-smoker. His only past illnesses have been herpes zoster in 1926 and pleurisy in 1942. There is no family history of psychological illness.

Clinical examination revealed a scotoma in the upper temporal quadrant of the left visual field : other systems appeared natural.

A blood examination gave $\mathrm{Hb} 100 \%$, W.B.C. 8,200 per c.mm., E.S.R. $3 \mathrm{~mm}$. The cerebrospinal fluid contained $48 \mathrm{mg}$. protein per $100 \mathrm{ml}$., no cells, and gave a normal Lange curve. The Wassermann reaction was negative.

A radiograph of the chest was normal.

An E.E.G. showed generalized abnormality, with episodic activity slower at the posterior part of the right hemisphere.

A radiograph of the skull showed a foreign body in the right temporal lobe (Fig. 2).



FIG. 2.-Case 3 : tracings of skull radiographs showing the position of the metal fragment (black) in the right temporal lobe. This entered the skull through the right orbit.

The patient's condition immediately improved on tabs. phenobarb., gr. $\frac{1}{4}$ t.d.s. He has had no further visual hallucinations, although he occasionally gets a " funny feeling in the stomach" such as commonly precedes such episodes.

\section{Discussion}

These three cases have many contrasting features. The first patient was imaginative and highly intelligent : he was a teacher and had formerly been legal adviser to the Polish General Staff. The subarachnoid haemorrhage was probably preceded by a small vascular lesion of the brain which provoked autoscopy. This persistent autoscopic hallucination, together with a vague feeling of malaise, were the only symptoms during the first two days. Throughout the course of the illness the only localizing sign in the central nervous system was a transient meningismus.

The onset of the hallucination was sudden and without warning ; it imposed on the patient's mind such a vivid conception of reality that on one 
occasion he drew up a chair for his double. This strong relationship between subject and image was also noted by Lhermitte (1951a, b), who mentions instances in which the patient has tried to tap his double on the shoulder.

The second patient was a labourer of low mentality who had been employed selling firewood before admission. In this case central localizing signs were manifest long before the onset of visual hallucinations. As the tumour developed, the patient's hallucinations gradually became more frequent and more highly organized, but it was only during the terminal phase of his illness that the patient recognized the image as being that of himself.

At necropsy it was found that almost the whole of the left parieto-occipital lobe was occupied by the main tumour mass, and a small seedling was also present in the left temporal lobe. The relationship between the site of cerebral irritation and the complexity of the visual hallucinations has been the subject of much speculation: it is generally held that temporal lobe tumours give rise to more complicated and more realistic hallucinations than those of the occipital lobe. Also, the latest studies on traumatic epilepsy by Russell and Whitty show that formed hallucinations more commonly result from wounds in the posterior temporal and high parieto-occipital areas (personal communication).

The third subject also provides a contrast to the previous cases, as 13 years elapsed between injury and the first autoscopic experience. It is significant that the hallucinations were banished by sedation. Subjectively this case is similar to one of cortical atrophy described by Critchley (1953). The patient believed that he was no longer alone and imagined the "presence" to be his own self. This "bipartition fantasy", Critchley writes, "lies at the crossroads between a temporary depersonalization, an heautoscopic hallucination and the phénomène de sosies."

Although there are many dissimilar features in the case histories of our three patients, yet they were in common all victims of focal brain lesions which in two of them could be localized to temporal and parieto-occipital areas. But evidence showing that autoscopy can in certain cases be associated with cerebral irritation in areas which are known to evoke formed hallucinations does not in itself explain the phenomenon. Yet it is along this entirely neurological approach that an explanation has hitherto been sought. Head and Holmes (1911) have shown that the sensorimotor systems are linked with the higher centres in relation to postural attitudes. Later Schilder (1933) developed the hypothesis that the individual possesses a notion of his physical being at the boundary of consciousness. This conception that our external actions are reflected in our psycho-physiological personalities was further developed by van Bogaert (1934). It has been variously described as the "postural scheme" (Head), the " body scheme" (Schilder), the "image of the self" (van Bogaert), and the " image of the corporal body" (Lhermitte, 1951 a, b). Indeed the latter suggests that an autoscopic hallucination should be regarded as a symptom of grave organic disease.

More recently Hécaen and de Ajuriaguerra (1952) have suggested a different neurological explanation. They divide organic cerebral lesions associated with autoscopy into two groups related to the areas of the cortex which they irritate. In the first group are epilepsy and focal lesions most commonly occurring in the parieto-occipital areas: toxicinfective states with a predilection for the basal areas form the second group. These latter conditions are said to provoke autoscopic hallucinations by "vegetative influences which act through the vestibuiar apparatus", or by "giving rise to an anxiety state".

These strictly neurological hypotheses fail to $\mathbb{\Phi}$ explain fully individual variations in the degree of complexity of hallucinations in general, and the occurrence of autoscopy in particular. It has long been known that, together with cerebral irritation, such individual variants as visual memory and the degree of visual imagery constitute a peculiarly subjective undertone to hallucinosis. Francis Galton (1883) was the pioneer in investigating the degree with which people can recall past sensations and see images in the mind's eye. He observed that visual memory varied greatly. To some people it had no meaning, whereas others were able to revive an early visual experience with hallucinatory clarity. The latter he called "visualizers"; at the other extreme are the congenitally blind, who never experience visual hallucinations (Wagener, 1948).

It would seem probable that amongst the visualizers are some (more than others) who possess this faculty of seeing a spatially localized mirror image of themselves, and we believe that it is amongst these subjects that the phenomenon of autoscopy is to be found. A focal organic lesion may, as in our cases, of course, be the precipitating stimulus, which either releases or facilitates the activity of the cerebral cortical area of recall, and thus presents before this corporal group of visualizers the unsubstantial shadow of themselves. 


\section{Summary}

Three cases of autoscopic hallucinations occurring in focal organic disease of the brain are presented and their contrasting fearures discussed.

It is tentatively suggested that autoscopic hallucinations (whatever the precipitating organic focal factor) occur only amongst a group of subjects with a highly developed visual memory sense of their corporal being.

We wish to thank Dr. W. Ritchie Russell, C.B.E., and Dr. C. W. M. Whitty for their help in the preparation of this paper, and also for allowing us to publish details of a patient (Case 3) under their care. Our thanks are also due to Dr. P. C. Mallam for permission to publish details of the first case, and to Dr. L. Z. Cosin for allowing us to publish case report No. 2 .

\section{REFERENCES}

Bogaert, Ludo van (1934). Ann. méd.-psychol., 92(2), 519.

Critchley, M. (1953). The Parietal Lobes. Arnold, London.

Galton, Francis (1883). Inquiries into Human Faculty and its Development. Macmillan, London.

Genner, T. (1947). Wien. klin.Wschr., 59, 656.

Head, H., and Holmes, G. (1911). Brain, 34, 102

Hécaen, H., and Ajuriaguerra, J. de (1952). Méconnaissances et Hallucinations Corporelles, pp. 310-338. Masson, Paris.

Lhermitte, J. (1937). Rev. méd. franc., 18, 235.

(1951a) Brit, med J. 1, 431.

(1951b). Les Hallucinations-Clinique et Physiopathologique. Doin, Paris.

Nouët, H. (1923). Encéphale, 18, 327.

Schilder, P. (1933). Amer. J. Psychiat., n.s. 13, 597.

Sivadon, P. (1937). Ann. méd. -psychol., 95(2), 215.

Skvortzoff, K. A. (1931). Vrac. Delo, 14, 1277.

Wagener, H. P. (1948). Amer. J. med. Sci., 215, 226. 